\title{
Physical activity level and associated factors among adult HIV patients in Ethiopia
}

Yadessa Tegene ${ }^{1 *}$, Selamawit Mengesha ${ }^{1}$, Caroline van der Starre ${ }^{3}$, Stephanie Lako ${ }^{3}$, Alemayehu Toma $^{2}$ and Mark Spigt ${ }^{3,4}$

\begin{abstract}
Background: People living with HIV, who take antiretroviral therapy (ART), often enjoy long and healthy lives, but this therapy has well known metabolic adverse effects. Physical activity is found to be an important factor in improving these physiological parameters. This study aimed to determine physical activity level and associated factors among HIV patients in Ethiopia.

Methods: An institutional based cross sectional study was conducted from May to June 2019. We selected a total of 422 adult HIV patients, attending antiretroviral therapy clinics in three selected hospitals in Southern Ethiopia. Data were collected at routine care consultations by nine trained nurses using a pre-tested structured questionnaire. The level of physical activity was measured by the international physical activity questionnaire (IPAQ).
\end{abstract}

Result: The mean age of participants was $38.7 \pm 9.13$ years. Of the participants, $68 \%$ were physically inactive, with a higher proportion of inactive women (74\%) than men (61\%) [(AOR=1.64,95\% Cl $(1.07,2.53)]$. In addition, urban vs. rural residents $[(A O R=2.57,95 \% \mathrm{Cl}(1.16,5.72)]$ and patients who were on $A R T$ for $\geq 24$ months $[(A O R=1.88,95 \% \mathrm{Cl}$ $(1.15,3.08)]$ had higher odds of having a low physical activity level.

Conclusion: Most people living with HIV and receiving ART have low physical activity levels. Especially female and urban living patients and those with longer treatment duration have low levels of physical activity. More insight is needed on the reasons for physical inactivity among HIV patients and physical activity programs for HIV patients in low-income countries need to be developed.

Keywords: Physical activity, People living with HIV, South Ethiopia

\section{Introduction}

In 2018, the estimated number of people living with HIV (PLWH) was 37.9 million, and $62 \%$ of them had access to life-saving antiretroviral medicines [1]. PLWH who take antiretroviral therapy (ART) can enjoy long and healthy lives [2]. This improvement caused the life expectancy of HIV patients and transformed HIV infection from an acute to a chronic disease [3]. However, the toxic side-effects of ART, long-term infection with HIV, the

\footnotetext{
*Correspondence: yadessategene@yahoo.com

${ }^{1}$ School of Public Health, College of Medicine and Health Science,

Hawassa University, Hawassa, Ethiopia

Full list of author information is available at the end of the article
}

increased predisposition to obesity, and visceral adiposity have made PLWH more vulnerable to develop comorbidities, such as cardiovascular disease $[4,5]$.

Past studies shown the benefit of physical activity in preventing and managing the adverse effects of ART [6]. Physical activity is any bodily movement produced by skeletal muscles that results in energy expenditure [7]. It improves physiological parameters such as cardiorespiratory fitness, muscular strength, waist circumference, insulin resistance, blood lipid profile, HIV-associated lipodystrophy, and systemic inflammation [4, 8-10]. Furthermore, it could also benefit the mental health status of 
HIV patients by improving depression status and reducing anxiety [11].

Globally, the physical activity status of HIV patients varies between countries, on average 32\% fall into the low physical activity category, the moderate and the high category, each accounts for $33 \%$, as defined by the International Physical Activity Questionnaire (IPAQ) [12]. According to a systematic review comparing physical activity correlates in HIV patients across 45 countries the largest percentage of HIV patients were inactive in South America (55\%) and highly active in North America (49\%) and low levels of physical activity are mainly associated with exposure to ART, presence of lipodystrophy, old age, and a lower CD4 count [13]. Higher levels of physical activity are predominantly associated with a high educational level [13].

There is limited information available on the levels and effects of physical activity on HIV/AIDS patients in Sub-Saharan Africa. A study conducted in Uganda, showed the positive effects of physical activity among HIV-infected people treated with ART, especially on metabolic and cardiovascular-related risks [14]. However, the literature indicates that despite the clear benefits of physical activity for PLWH, studies on engagement in adequate physical activity are still limited. The main sources of physical activity in Ethiopia are related to work and transport [15]. It is expected that PLWH have lower physical activity levels as compared to the general Ethiopian population, as PLWH might be less capable of performing physical activities.

Currently, alike other parts of sub Saharan countries, the accessibility of ART for Ethiopian HIV patients is increasing and it is well known that this therapy is associated with adverse effects. Engaging in regular physical activity is one way to prevent and/or treat this adverse effect. Therefore, this research aims to assess the status of physical activity and examines the factors associated with the level of physical activity among adult PLWH in Ethiopia. The information obtained from this study provides useful information to design strategies in improving physical activity status and prevention of risks associated with physical inactivity among adult HIV patients.

\section{Methods}

\section{Study design, setting, participants and sampling}

This study was conducted using a cross-sectional design in three selected hospitals, one comprehensive specialized hospital and two general hospitals from May to June 2019. Hawassa University Comprehensive Specialized Hospital (HUCSH), a tertiary level hospital, delivers specialized and referral services for general hospitals. The two general hospitals, Adare and Yirgalem, deliver secondary level health care, providing preventive and curative services that require diagnostic facility and therapeutic intervention [16]. HUCSH and Adare general hospitals are found in Hawassa town, the capital of the Sidama regional state, and the South Nation Nationality Peoples Region (SNNPR) of Ethiopia, which is located, $275 \mathrm{~km}$ south of Addis Ababa, the capital of Ethiopia. HUCSH, Adare, and Yirgalem general hospitals at the beginning of this study gave ART service for 2553, 1821, and $1476 \mathrm{HIV}$ patients respectively.

The study sample was selected from adult HIV patients (18 years plus), enrolled in ART care and visiting the three selected hospitals during the study period. Pregnant and lactating women were excluded from the study. A single population proportion formula was used to calculate the sample size. So far, there was no similar study conducted in the area or elsewhere having the same status as in Ethiopia. Therefore, the estimated proportion of $50 \%$ was taken to have maximum sample size. A sample of 384 was obtained and by considering the $10 \%$ non-response rate, the final sample size became 422 . Proportional allocation was used to determine the number of study units to be sampled from each facility. Based on this, 184, 131 and 107 study participants were selected from HUCSH, Adare, and Yirgalem general hospitals, respectively. Individual study participants were selected by random arrival at the ART clinic.

\section{Data collection methods and procedures}

Data were collected through interview administered questionnaires, conducted at routine consultation by nine trained nurses. A structured questionnaire was used to collect information on socioeconomic and ARTrelated characteristics of the study participants. To collect data on the level of physical activity of the participants, we used the the short form IPAQ [17]. Since several examples of physical activity were not regular activities in Ethiopia, we replaced these by other physical activities with approximately the same Metabolic Equivalent of Task (MET) [18]. In the category of vigorous physical activity, fast bicycling was replaced by rope jumping. In the category of moderate physical activity, bicycling at a regular pace and double tennis was replaced by cleaning and gardening. After the cultural adaptation, the questionnaire was translated to Amharic and retranslated to the original version to check for consistency. We have presented the data on physical exercise as a continuous score using MET-min per week (MET level $\times$ minutes of activity $\times$ events per week) or as a categorical variable in three categories: low, moderate, and high. Participants who did not fulfill the criteria of moderate and high were considered as low active or inactive.

Participants who fulfilled one of the following criteria were categorized in the moderate group. 
- Performing at least 20 min of vigorous activity on 3 or more days a week or;

- Performing moderate-intensity activity or walking for at least $30 \mathrm{~min}$ on 5 or more days a week or;

- Any combination of moderate-intensity activity, vigorous activity or walking on 5 or more days achieving at least 600 MET-min per week.

Participants were categorized into the high activity group, if they fulfilled one of the following criteria:

- Performing vigorous-intensity activity on a minimum of 3 days a week and achieving at least 1500 METmin per week or;

- Any combination of moderate-intensity activity, vigorous activity or walking on 7 days achieving at least 3000 MET-min per week.

Dietary diversity and household food insecurity data were collected using the Food and Nutrition Technical Assistance (FANTA) indicator guide for Household Dietary Diversity Score (HDDS) [19] and Household Food Insecurity Access Scale (HFIAS) [20] respectively. Anthropometric measurements, such as height, was measured using a stadiometer (Seca Germany) by positioning the patient at the Frankfert plane recorded to the nearest $0.1 \mathrm{~cm}$. Weight was measured using a pretested and calibrated digital Seca ${ }^{\circledR}$ scale and recorded to the nearest $0.1 \mathrm{~kg}$.

Blood pressure (BP) was measured with the standard mercury sphygmomanometer BP cuff with the appropriate cuff size by measuring the left arm consistently, three times at a 5-min interval. The average of the two last readings was taken, and the diagnosis of high BP (hypertension) was made according to the WHO criteria as systolic $\mathrm{BP} \geq 140 \mathrm{mmHg}$ or diastolic $\mathrm{BP} \geq 90 \mathrm{mmHg}$ [21]. Random blood glucose levels were determined by using Fia Biomed Blood Glucose Meter (Glucometer) Salut by finger puncture. According to the American Diabetes Association's guideline, fasting plasma glucose levels $\geq 126 \mathrm{mg} / \mathrm{dL}, 2 \mathrm{~h}$ plasma glucose $\geq 200 \mathrm{mg} / \mathrm{dL}$ during oral glucose tolerance test, hemoglobin $\mathrm{A} 1 \mathrm{C} \geq 6.5 \%$ and in a patient with classic symptoms of hyperglycemia or hyperglycemic crisis a random plasma glucose $\geq 200 \mathrm{mg} /$ $\mathrm{dL}$ are defind as diabetes [22]. Participants who were unaware of the fact that they had diabetes and/or hypertension were linked to the respective hospital for further diagnosis and management of their conditions.

\section{Data management and analysis}

Data were analyzed using SPSS for windows version 20.0 (IBM, USA). Descriptive statistics were presented in the form of frequency, percentage, mean and standard deviation. Chi square test was used to assess the association between categorical variables. Variables having $P$-value $<0.25$ in the bivariate logistic regression analyses were considered as potential candidates in the final multivariable logistic regression analysis. $P$-value $<0.05$ was used to declare statistical significance in the multivariable model. The overall goodness of fit of the model was checked by using Hosmer-Lemeshow. Finally, the adjusted odds ratio (AOR) with its $95 \%$ confidence interval $(\mathrm{CI})$ was used to determine statistical significance.

\section{Results}

\section{Socio-demographic characteristics of adults living} with HIV/AIDS

We included a sample of 422 adult HIV patients receiving ART service from three selected public hospitals. Most participants $(64 \%)$ were women and from an urban area (93\%), with a mean age of $38.7 \pm 9.13$ years. Nearly half of the participants $(48 \%)$ were married and had a monthly household income of $\leq 1500$ Ethiopian Birr (52\%). The majority of participants (37\%) had completed secondary education and about $28 \%$ were privately employed (Table 1).

\section{Clinical and nutrition related characteristics of adult people living with HIV/AIDS}

More than half of the participants (58\%) had a recent CD4 count that was $\geq 500$ cells $/ \mathrm{mm}^{3}$ and most patients had normal BMI (59\%). Majority of the participants (92.2\%) were in clinical stage I, had been on treatment for $\geq 2$ years $(70 \%)$, had no chronic comorbidity $(11 \%)$, and household food insecurity (75\%) (Table 2).

\section{Physical activity levels}

We observed significant relationship between gender and PA level $\left(X^{2}=6.08, P \leq 0.048\right)$, where men were, in general, more physically active than women. Participants living in rural areas were found to have more overall PA $(P=0.007)$ compared to other urban living study participants (Table 3).

\section{Physical activity level of the study participants}

More than half of the participants, 288 (68\%) had low PA levels, followed by moderate, 75 (18\%) and high 59 (14\%) respectively (Fig. 1). More, 194 (72\%) women were physically inactive compared to men 94 (61\%) (Fig. 2).

\section{Factors associated with physical activity level among adults living with HIV/AIDS}

In bivariate logistic regression analysis; gender, place of residence, duration of treatment and HHFIS were factors associated with physical activity level. In multiple logistic regression analysis; gender, place of residence 
Table 1 Socio-demographic characteristics of people living with HIV/AIDS attending ART clinic $(n=422)$

\begin{tabular}{|c|c|c|}
\hline Variables & Frequency & Percent \\
\hline \multicolumn{3}{|l|}{ Age } \\
\hline$<20$ & 8 & 2 \\
\hline $21-30$ & 75 & 18 \\
\hline $31-40$ & 192 & 45 \\
\hline $41-50$ & 102 & 24 \\
\hline $51-60$ & 45 & 11 \\
\hline \multicolumn{3}{|l|}{ Gender } \\
\hline Male & 154 & 36 \\
\hline Female & 268 & 64 \\
\hline \multicolumn{3}{|l|}{ Marital status } \\
\hline Single & 203 & 48 \\
\hline Married & 65 & 15 \\
\hline Divorced & 75 & 18 \\
\hline Widowed & 79 & 19 \\
\hline \multicolumn{3}{|l|}{ Occupation } \\
\hline Government employee & 95 & 23 \\
\hline Private employee & 118 & 28 \\
\hline Daily-laborer & 49 & 12 \\
\hline House wife & 9 & 2 \\
\hline Merchant & 65 & 15 \\
\hline Others & 86 & 20 \\
\hline \multicolumn{3}{|l|}{ Educational level } \\
\hline No formal education & 44 & 10 \\
\hline Primary education & 114 & 27 \\
\hline Secondary education & 155 & 37 \\
\hline Tertiary education & 109 & 26 \\
\hline \multicolumn{3}{|l|}{ Place of residence } \\
\hline Urban & 394 & 93 \\
\hline Rural & 28 & 7 \\
\hline \multicolumn{3}{|l|}{ Income level } \\
\hline$<\$ 33.98$ & 218 & 52 \\
\hline$\geq \$ 33.98$ & 204 & 48 \\
\hline
\end{tabular}

Private Employee $=$ A person who works for a private employer or in private organization and receives regular remuneration in salary

1 USD $=44.15$ Ethiopian Birr, 2021

and duration of treatment remained significantly associated with physical activity level of participants. Women participants were two times $[(\mathrm{AOR}=1.64,95 \%$ CI $(1.07,2.53)]$ more likely to be physically inactive than men. Participants from urban residence were three times $[(\mathrm{AOR}=2.57,95 \% \mathrm{CI}(1.16,5.72)]$ more likely to be physically inactive than rural patients. Participants, who had been on ART for $\geq 24$ months were nearly two times $[(\mathrm{AOR}=1.88,95 \% \mathrm{CI}(1.15,3.08)]$ more likely to be physically inactive than those who were on ART for $<24$ months (Table 4).
Table 2 Clinical and nutrition related characteristics of people living with HIV/AIDS attending ART clinic $(n=422)$

\begin{tabular}{|c|c|c|}
\hline Variables & Frequency & Percent \\
\hline \multicolumn{3}{|l|}{ CD4 count } \\
\hline$<200$ & 44 & 10 \\
\hline $200-349$ & 62 & 15 \\
\hline $350-499$ & 72 & 17 \\
\hline$\geq 500$ & 244 & 58 \\
\hline \multicolumn{3}{|l|}{ WHO clinical stage } \\
\hline Stage I & 389 & 92 \\
\hline Stage II & 15 & 3 \\
\hline Stage III & 16 & 4 \\
\hline Stage IV & 2 & 1 \\
\hline \multicolumn{3}{|l|}{ Drug regimen } \\
\hline AZT-3TC-EFV & 68 & 16 \\
\hline AZT-3TC-NVP & 80 & 19 \\
\hline TDF-3TC-EFV & 217 & 51 \\
\hline Others & 57 & 14 \\
\hline \multicolumn{3}{|c|}{ Duration of treatment in months } \\
\hline$<24$ & 126 & 30 \\
\hline$\geq 24$ & 296 & 70 \\
\hline \multicolumn{3}{|c|}{ Chronic comorbidity } \\
\hline No & 375 & 89 \\
\hline Yes & 47 & 11 \\
\hline \multicolumn{3}{|l|}{ BMI } \\
\hline Underweight & 63 & 15 \\
\hline Normal & 247 & 59 \\
\hline Overweight & 112 & 26 \\
\hline \multicolumn{3}{|l|}{ HHFIS } \\
\hline Secured & 107 & 25 \\
\hline Unsecured & 315 & 75 \\
\hline
\end{tabular}

\section{Discussion}

We assessed the level of physical activity and the associated factors among HIV patients attending ART clinics of public hospitals in South Ethiopia. The current study showed a high proportion of physically inactive HIV patients, and women participants take the largest share of this proportion. Being an urban resident and a longer duration of treatment were also factors that were associated with physical inactivity.

In the current study, a high proportion (68\%) of HIV patients attending the ART clinic was physically inactive. This result is consistent with study conducted in Malawi, which showed percentage of $40 \%$ [23]. These earlier studies indicated that being older was a leading reason for low PA among PLWHA [13]. In our study the majority of participants $(89 \%)$ were younger aged ( $<50$ years) with the mean age of 38.7 years. In addition, we excluded pregnant and lactating women. Therefore, being pregnant did 
Table 3 Domain-specific physical activity level among adults living with HIV/AIDS attending ART clinic, in three selected public hospitals of South Ethiopia, 2019, $(n=422)$

\begin{tabular}{|c|c|c|c|c|c|c|c|}
\hline \multirow[t]{3}{*}{ Variables } & \multicolumn{6}{|c|}{ Physical activity level } & \multirow[t]{3}{*}{$X^{2}$-P-value } \\
\hline & \multicolumn{2}{|c|}{ Low } & \multicolumn{2}{|c|}{ moderate } & \multicolumn{2}{|c|}{ Vigorous } & \\
\hline & $\mathbf{N}$ & $\%$ & $\mathbf{N}$ & $\%$ & $\mathbf{N}$ & $\%$ & \\
\hline \multicolumn{8}{|l|}{ Gender } \\
\hline Male & 94 & 33 & 35 & 47 & 25 & 42 & \multirow[t]{2}{*}{$0.48^{*}$} \\
\hline Female & 194 & 67 & 40 & 53 & 34 & 58 & \\
\hline \multicolumn{8}{|l|}{ CD4 count } \\
\hline$<200$ & 35 & 12 & 6 & 8.0 & 3 & 5 & \multirow[t]{4}{*}{0.16} \\
\hline $200-349$ & 40 & 14 & 16 & 21 & 6 & 10 & \\
\hline $350-499$ & 47 & 16 & 10 & 13 & 15 & 25 & \\
\hline$\geq 500$ & 166 & 58 & 43 & 57 & 35 & 59 & \\
\hline \multicolumn{8}{|l|}{ Educational level } \\
\hline No formal education & 31 & 11 & 8 & 11 & 5 & 9 & \multirow[t]{3}{*}{0.95} \\
\hline Primary education & 79 & 27 & 18 & 24 & 17 & 29 & \\
\hline Secondary and above & 178 & 62 & 49 & 65 & 37 & 63 & \\
\hline \multicolumn{8}{|l|}{ Place of residence } \\
\hline Urban & 275 & 96 & 64 & 85 & 55 & 93 & \multirow[t]{2}{*}{$0.007^{*}$} \\
\hline Rural & 13 & 5 & 11 & 15 & 4 & 7 & \\
\hline \multicolumn{8}{|l|}{ BMI } \\
\hline Under weight $(\leq 18.5)$ & 43 & 15 & 10 & 13 & 10 & 17 & \multirow[t]{3}{*}{0.93} \\
\hline Normal (18.5-24.9) & 166 & 58 & 47 & 63 & 34 & 58 & \\
\hline Over weight ( $\geq 25$ ) & 79 & 27 & 18 & 24 & 15 & 25 & \\
\hline \multicolumn{8}{|l|}{ Occupation } \\
\hline Government employee & 68 & 24 & 15 & 20 & 12 & 20 & \multirow[t]{6}{*}{0.69} \\
\hline Private employee & 83 & 29 & 15 & 20 & 20 & 34 & \\
\hline Daily-laborer & 34 & 12 & 8 & 11 & 7 & 12 & \\
\hline House wife & 6 & 2 & 2 & 3 & 1 & 2 & \\
\hline Merchant & 39 & 14 & 16 & 21 & 10 & 17 & \\
\hline Others & 58 & 20 & 19 & 25 & 9 & 15 & \\
\hline
\end{tabular}

${ }^{*} \mathrm{P} \leq 0.05$

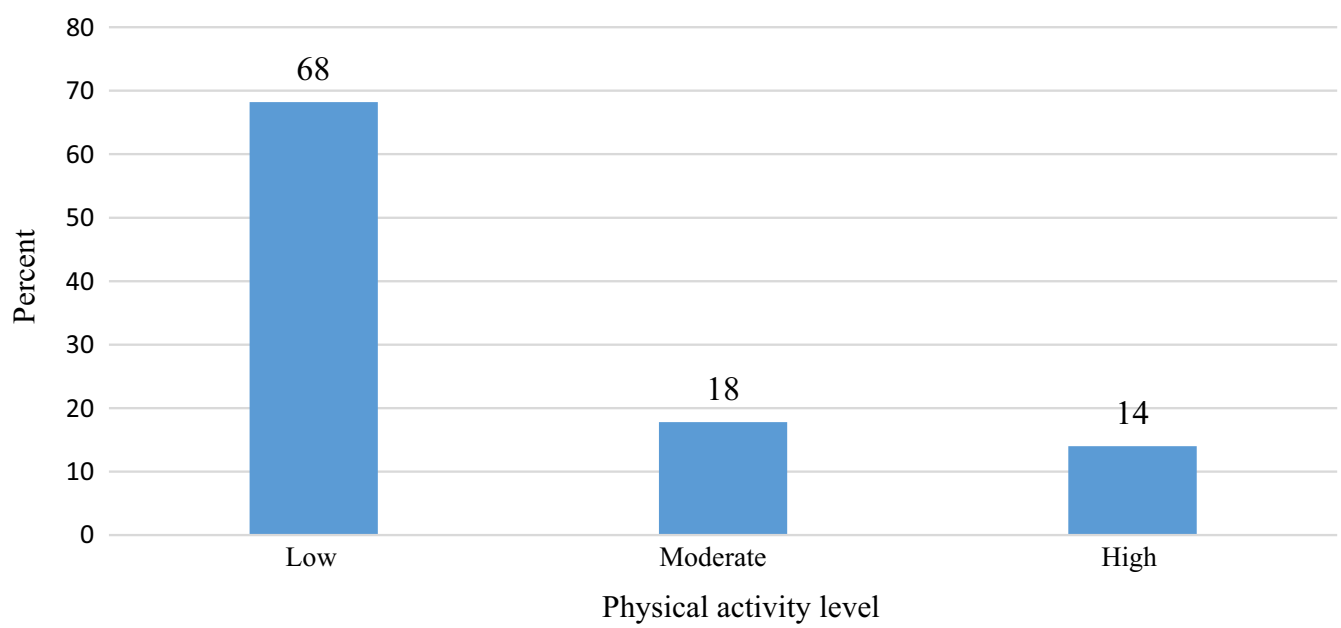

Fig. 1 Physical activity levels of people living with HIV/AIDS attending ART clinic, in three selected public hospital of South Ethiopia, 2019, ( $n=422)$ 


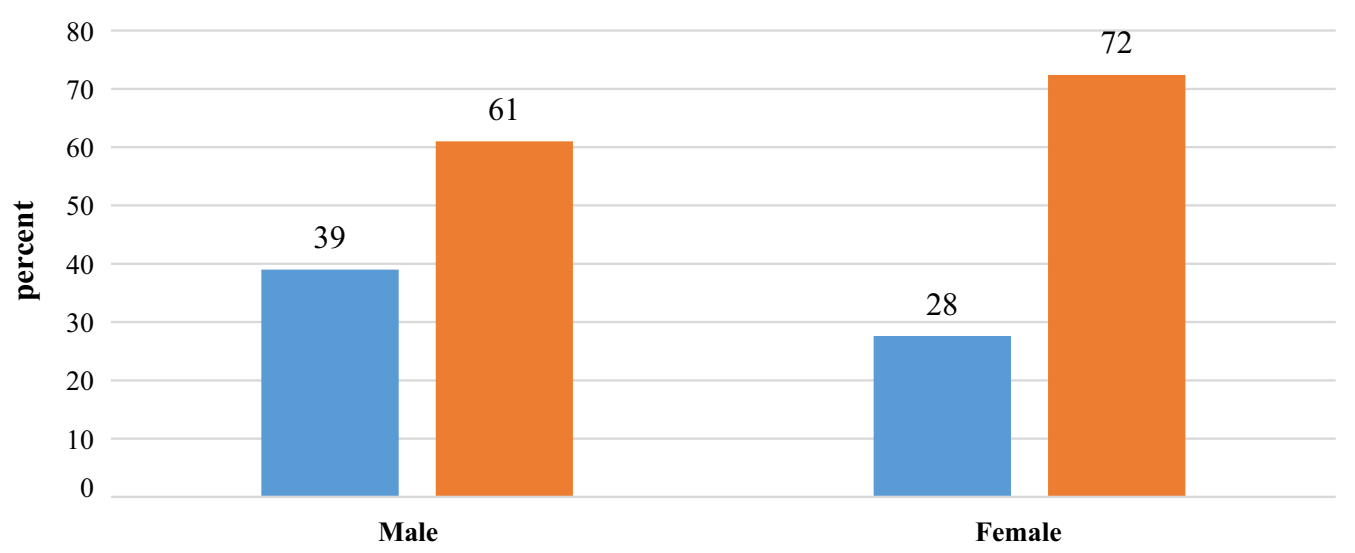

Physical activity level

Active Inactive

Fig. 2 Gender stratified physical activity levels of people living with HIV/AIDS attending ART clinic, in three selected public hospital of South Ethiopia, 2019, $(n=422)$

Table 4 Factors associated with low levels of physical activity among adults living with HIV/AIDS attending ART clinic, in three selected public hospitals of South Ethiopia, 2019, $(n=422)$

\begin{tabular}{|c|c|c|c|c|}
\hline \multirow[t]{2}{*}{ Variable } & \multicolumn{2}{|c|}{$\begin{array}{l}\text { Low physical } \\
\text { activity }\end{array}$} & \multirow[t]{2}{*}{$\operatorname{COR}(95 \% \mathrm{Cl})$} & \multirow[t]{2}{*}{ AOR $(95 \% \mathrm{Cl})$} \\
\hline & No $N(\%)$ & Yes N (\%) & & \\
\hline \multicolumn{5}{|l|}{ Gender } \\
\hline Male & $60(39)$ & $94(61)$ & 1 & 1 \\
\hline Female & $74(28)$ & $194(72)$ & $1.67(1.11-2.55)^{*}$ & $1.64(1.07,2.53)^{*}$ \\
\hline \multicolumn{5}{|c|}{ Place of residence } \\
\hline Urban & $119(30)$ & $275(70)$ & $2.67(1.23,5.78)^{*}$ & $2.57(1.16,5.72)^{*}$ \\
\hline Rural & $15(54)$ & $13(46)$ & 1 & 1 \\
\hline \multicolumn{5}{|c|}{ Duration of treatment ( months) } \\
\hline$<24$ & $29(23)$ & $97(77)$ & 1 & 1 \\
\hline$\geq 24$ & $105(35)$ & $191(65)$ & $1.84(1.14,2.97)^{*}$ & $1.88(1.15,3.08)^{*}$ \\
\hline \multicolumn{5}{|l|}{ HHFIS } \\
\hline Secured & $29(27)$ & $78(73)$ & 1 & 1 \\
\hline Unsecured & $105(33)$ & $210(67)$ & $1.35(0.83,2.19)$ & $0.74(0.45,1.23)$ \\
\hline
\end{tabular}

* Statistically significant variables in multiple logistic regressions at P-value $\leq 0.05$

not explain the lower PA in the current study. Since the lower PA level was observed among younger and productive groups of the society, this poses a challenge in the economy of the country in addition to exposing them to an associated risk of chronic comorbidities. Therefore, physical activity interventions should get attention in the routine HIV management programs of the country.

In our study, a higher number of women were physically inactive. Consistent findings were seen in several studies conducted elsewhere in Africa [15, 23, 24]. In the current study area, men are involved more often in intensive manual labors, like agricultural activities, construction and often carrying heavy weights, than women. In addition, in the current study set up, women have less chance to engage in different recreational and regular physical exercise activities. Therefore, interventions aimed at promoting physical activity should target adult female HIV patients.

In the current study, participants residing in urban areas had higher odds of low PA than those in rural areas. This finding is in line with the studies conducted in sub-Saharan Africa countries, Northern Tanzania and Vietnam [25, 26]. In Ethiopia, people living in the rural area are more often involved in vigorous and moderate activities than urban people, because more manual labor and agricultural activities are found in the rural area than urban. In addition, most Ethiopian rural setups do not have transportation access, and due to that people walk long distances from one farm site to another or from place to place for various social issues. In addition, rural dwellers tend to practice manual work and active travel, which insures vigorous and moderate PA, while their urban counterparts seem to adopt sedentary lifestyles. Therefore, to avoid the additional burden of chronic comorbidity, it is vital to promote physical activity among urban PLWH as an intervention strategy.

The other variable that has shown a significant association with physical inactivity was the duration of treatment. Physical inactivity was more common among participants who stayed on ART for more than 2 years. Our finding is consistent with a study conducted 
in Vietnam [25]. The possible reason could be that patients may have more commitment at the initiation of treatment due to their health condition and the frequent counseling and follow-up they get from health care providers. Maybe, when their health status is stable in the later stages, they become less compliant to adhere to the care taken. Health care providers should consider developing peer support programs, regular follow-up and awareness creation to increase the level of physical activity and overall health status.

As a limitation, during our assessment of physical activity level, data were collected based on selfreported information, which is subjected to social desirability bias and results in over reporting of physical activity. Since participants were asked about their physical activity of 1-week duration, their response may also be subjected to recall bias. To minimize the bias, clear instruction was given on the objective, benefit and drawback of the study both for participants and data collectors.

\section{Conclusion}

In our study most people living with HIV and receiving ART have low physical activity levels. Our study revealed the significant association between being female, urban residents and longer duration of treatment with physical inactivity. There is a need for physical activity programs for HIV patients.

\begin{abstract}
Abbreviations
AIDS: Acquired immune deficiency virus; AOR: Adjusted odds ratio; ART : Antiretroviral therapy; BP: Blood pressure; BMI: Body Mass Index; Cl: Confidence interval; COR: Crude odds ratio; DM: Diabetes Mellitus; HHFIS: House Hold Food Insecurity Scale; HIV: Human immune virus; HUCSH: Hawassa University Comprehensive Specialized Hospital; IDDS: Individual Dietary Diversity Score; IPAQ: International Physical Activity Questionnaire; MET: Metabolic Equivalent of Task; NCD: Non-communicable disease; PLWH: People living with HIV; PA: Physical activity; SD: Standard deviation; SPSS: Statistical Package for the Social Sciences; WHO: World Health Organization.
\end{abstract}

\section{Acknowledgements}

We thank Hawassa University, College of Medicine and Health Sciences for providing fund for the study. We would like to thank also the data collectors and the study participants.

\section{Authors' contributions}

YT, SM, AT, MS, conceived and designed the study. YT obtained the data, analyzed and wrote original draft. YT, SM, AT, MS interpreted and critically revised the manuscript. All authors read and approved the final manuscript.

\section{Funding}

This research work was financed by Hawassa University, College of Medicine and Health Sciences, Ethiopia. The funder had no role in study design, data collection and analysis, decision to publish, or preparation of the manuscript.

\section{Availability of data and materials}

The datasets used and/or analyzed during the current study are available from the corresponding author on reasonable request.

\section{Declarations}

\section{Ethics approval and consent to participate}

To conform with the Declaration of Helsinki (1964) and Population Screening Act, ethical approval for the study was obtained from Hawassa University College of Medicine and Health Sciences institutional review board (IRB/216/2019). Permission was obtained from the hospital management. Participation was determined by the person without any external influence to participate or not. Before the data collection, informed written consent (signed or verified by fingerprint) was taken from the study subjects. The data were collected and analyzed anonymously.

\section{Consent for publication}

Not applicable.

\section{Competing interests}

The authors declare that they have no competing interests.

\section{Author details}

${ }^{1}$ School of Public Health, College of Medicine and Health Science, Hawassa University, Hawassa, Ethiopia. ${ }^{2}$ School of Medicine, College of Medicine and Health Science, Hawassa University, Hawassa, Ethiopia. ${ }^{3}$ School CAPHRI, Department of Family Medicine, Maastricht University, Maastricht, Netherlands. ${ }^{4}$ General Practice Research Unit, Department of Community Medicine, UiT the Arctic University of Norway, Tromsö, Norway.

Received: 16 April 2021 Accepted: 24 January 2022

Published online: 04 February 2022

\section{References}

1. Mahy M, Marsh K, Sabin K, Wanyeki I, Daher J, Ghys PD. HIV estimates through 2018: data for decision-making. AIDS (Lond, Engl). 2019;33(Suppl 3):S203.

2. Pérez F, Ravasi G, Figueroa JP, Grinsztejn B, Kamb M, Sued O, et al. HIV/ AIDS prevention, care and treatment in the Region of the Americas: achievements, challenges and perspectives. Rev Panam Salud Publica. 2016:40:398-400

3. Trickey A, May MT, Vehreschild J-J, Obel N, Gill MJ, Crane HM, et al. Survival of HIV-positive patients starting antiretroviral therapy between 1996 and 2013: a collaborative analysis of cohort studies. Lancet HIV. 2017:4(8):e349-56.

4. Lake JE. The fat of the matter: obesity and visceral adiposity in treated HIV infection. Curr HIV/AIDS Rep. 2017;14(6):211-9.

5. Webel AR, Perazzo J, Longenecker CT, Jenkins T, Sattar A, Rodriguez M, et al. The influence of exercise on cardiovascular health in sedentary adults with HIV. J Cardiovasc Nurs. 2018;33(3):239.

6. Jaggers JR, Hand GA. Health benefits of exercise for people living with HIV: a review of the literature. Am J Lifestyle Med. 2016;10(3):184-92.

7. Piggin J. What is physical activity? A holistic definition for teachers, researchers and policy makers. Front Sports Act Living. 2020;2:72.

8. Dirajlal-Fargo S, Webel AR, Longenecker CT, Kinley B, Labbato D, Sattar A, et al. The effect of physical activity on cardiometabolic health and inflammation in treated HIV infection. Antivir Ther. 2016;21(3):237.

9. Forde C, Loy A, O'Dea S, Mulcahy F, Gormley J, Daly C. Physical activity is associated with metabolic health in men living with HIV. AIDS Behav. 2018;22(6):1965-71.

10. Kamitani E, Sipe TA, Higa DH, Mullins MM, Soares J, Project CHAPRS. Evaluating the effectiveness of physical exercise interventions in persons living with HIV: overview of systematic reviews. AIDS Educ Prev. 2017;29(4):347-63.

11. Nosrat S, Whitworth JW, Ciccolo JT. Exercise and mental health of people living with HIV: a systematic review. Chronic IIIn. 2017;13(4):299-319.

12. Vancampfort D, Mugisha J, De Hert M, Probst M, Firth J, Gorczynski P, et al: Global physical activity levels among people living with HIV: a systematic review and meta-analysis. Disabil Rehabil. 2018;40(4):388-97.

13. Vancampfort D, Mugisha J, Richards J, De Hert M, Probst M, Stubbs B. Physical activity correlates in people living with HIV/AIDS: a systematic review of 45 studies. Disabil Rehabil. 2018;40(14):1618-29. 
14. Kazooba P, Kasamba I, Mayanja BN, Lutaakome J, Namakoola I, Salome T, et al. Cardiometabolic risk among HIV-POSITIVE Ugandan adults: prevalence, predictors and effect of long-term antiretroviral therapy. Pan Afr Med J. 2017;27(1)

15. Mengesha MM, Roba HS, Ayele BH, Beyene AS. Level of physical activity among urban adults and the socio-demographic correlates: a population-based cross-sectional study using the global physical activity questionnaire. BMC Public Health. 2019;19(1):1-11.

16. Standard E. Ethiopian standard. Primary, general and Comprehensive Specialized hospitals requirements. 2012.

17. Craig C, Marshall A, Sjostrom M, Bauman A, Lee P, Macfarlane D, et al. International physical activity questionnaire-short form. J Am Coll Health. 2017;65(7):492-501.

18. Riley L, Guthold R, Cowan M, Savin S, Bhatti L, Armstrong T, et al. The World Health Organization STEPwise approach to noncommunicable disease risk-factor surveillance: methods, challenges, and opportunities. Am J Public Health. 2016;106(1):74-8.

19. Swindale A, Bilinsky P. Household dietary diversity score (HDDS) for measurement of household food access: indicator guide. Washington, DC: Food and Nutrition Technical Assistance Project, Academy for Educational Development; 2006

20. Coates J, Swindale A, Bilinsky P. Household Food Insecurity Access Scale (HFIAS) for measurement of food access: indicator guide: version 3. 2007.

21. Organization WH. Guideline for the pharmacological treatment of hypertension in adults. Geneva: WHO; 2021

22. Association AD. 2. Classification and diagnosis of diabetes: standards of medical care in diabetes-2020. Diabetes Care. 2020;43(1):S14-31.

23. Chisati E. Physical activity levels among Malawian adults living with HIV and receiving anti-retroviral therapy. Malawi Med J. 2020;32(1):8-12.

24. Mashili FL, Mbatia J, Nana A, Saguti G, Kagaruki G. Physical activity and associated socioeconomic determinants in rural and urban Tanzania: results from the 2012 WHO-STEPS Survey. 2018.

25. Dang AK, Nguyen LH, Nguyen AQ, Tran B, Tran T, Latkin C. Physical activity among HIV-positive patients receiving antiretroviral therapy in Hanoi and Nam Dinh, Vietnam: a cross-sectional study. BMJ Open. 2018;8(5):e020688.

26. John B, Todd J, Mboya I, Mosha M, Urassa M, Mtuy T. Physical activity and associated factors from a cross-sectional survey among adults in northern Tanzania. BMC Public Health. 2017;17(1):588.

\section{Publisher's Note}

Springer Nature remains neutral with regard to jurisdictional claims in published maps and institutional affiliations.

Ready to submit your research? Choose BMC and benefit from:

- fast, convenient online submission

- thorough peer review by experienced researchers in your field

- rapid publication on acceptance

- support for research data, including large and complex data types

- gold Open Access which fosters wider collaboration and increased citations

- maximum visibility for your research: over $100 \mathrm{M}$ website views per year

At BMC, research is always in progress.

Learn more biomedcentral.com/submissions 